\title{
Assistência farmacêutica nas consequências do uso de anfetaminas por motoristas de caminhão: revisão integrativa
}

Pharmaceutical assistance in the consequences of amphetamine use by truck drivers: integrative review

Asistencia farmacéutica en las consecuencias del consumo de anfetaminas por parte de los conductores de camiones: revisión integradora

\section{Resumo}

O uso de anfetaminas é considerado um problema de saúde pública, pois estão entre as drogas mais utilizadas mundialmente. O seu consumo é comum entre caminhoneiros para reduzir seu tempo nas estradas chegando rapidamente ao seu destino. Nas drogarias as consequências relatadas para os farmacêuticos após o efeito de seu uso são distúrbios do sono, irritabilidade, agitação nervosa, lapsos de memória e hipertensão e nesse momento deverá ocorrer a assistência farmacêutica para orientar sobre os perigos de seu uso. Mostrar como a assistência farmacêutica pode auxiliar nos cuidados as consequências do uso de anfetaminas por motoristas de caminhão. Os materiais utilizados foram artigos publicados entre os anos de 2016 a 2021, pesquisados nas plataformas de pesquisa: SciELO (Scientific Eletronic Library Online) e Google Acadêmico. Os métodos utilizados são: revisão sistemática da literatura, com aplicação do método qualitativo de pesquisa. Estudos mostram que os caminhoneiros ao consumir anfetaminas levam o SNC - Sistema Nervoso Central a captar ações e através de mediadores respondem com estímulos de destreza, autoconfiança e inibindo o sono e os motoristas se arriscam nas rodovias por prolongarem sua jornada sem descanso e como consequências podem provocar efeitos rebote causando acidentes evolvendo outras pessoas devido a oscilação de respostas no SNC. O uso de anfetaminas por caminhoneiros é uma das principais caudas de acidentes nas estradas e rodovias incluindo vítimas fatais geradas por seus efeitos e os farmacêuticos durante a assistência devem orientar que o uso dessas substâncias pode trazer riscos consideráveis a saúde, incluído as doenças crônicas.

Palavras-chave: Anfetaminas; Assistência farmacêutica; Caminhão; Motoristas.

\begin{abstract}
The use of amphetamines is considered a public health problem, as they are among the most used drugs worldwide. Its consumption is common among truck drivers to reduce their time on the road quickly arriving at their destination. In drugstores, the consequences reported to pharmacists after the effect of its use are sleep disturbances, irritability, nervous agitation, memory lapses and hypertension, and at that time, pharmaceutical assistance should be provided to advise on the dangers of its use. Show how pharmaceutical assistance can help in caring for the consequences of the use of amphetamines by truck drivers. The materials used were articles published between the years 2016 to 2021 , searched on the research platforms: SciELO (Scientific Electronic Library Online) and Google Scholar. The methods used are: systematic literature review, applying the qualitative research method. Studies show that when truck drivers consume amphetamines, the CNS - Central Nervous System takes action and, through mediators, respond with stimuli of dexterity, self-confidence and inhibiting sleep, and drivers take risks on the highways for prolonging their journey without rest and as consequences can cause rebound effects causing accidents involving other people due to oscillating responses in the CNS. The use of amphetamines by truck drivers is one of the main causes of accidents on
\end{abstract}


roads and highways, including fatalities generated by its effects and pharmacists during assistance should advise that the use of these substances can bring considerable health risks, including chronic diseases.

Keywords: Amphetamines; Pharmaceutical care; Truck; Drivers.

\section{Resumen}

El consumo de anfetaminas se considera un problema de salud pública, ya que se encuentran entre las drogas más utilizadas en todo el mundo. Su consumo es común entre los camioneros para reducir su tiempo en las carreteras llegando rápidamente a su destino. Mostrar cómo la atención farmacéutica puede ayudar en el cuidado de las consecuencias del consumo de anfetaminas por parte de los conductores de camiones. Los materiales utilizados fueron artículos publicados entre 2016 y 2021, investigados en las plataformas de investigación: SciELO (Scientific Electronic Library Online) y Google Scholar. Los métodos utilizados son: revisión sistemática de la literatura, con aplicación del método cualitativo de investigación. Los estudios demuestran que los camioneros al consumir anfetaminas llevan al SNC - Sistema Nervioso Central a captar acciones y a través de mediadores responden con estímulos de destreza, autoconfianza e inhibición del sueño y los conductores corren el riesgo en las carreteras por prolongar su viaje sin descanso y como consecuencias pueden provocar efectos de rebote provocando accidentes evolucionando a otras personas debido a la oscilación de las respuestas en el SNC. El uso de anfetaminas por parte de los camioneros es una de las principales colas de accidentes en carreteras y autopistas, incluidas las muertes generadas por sus efectos y los farmacéuticos durante la asistencia deben guiar que el uso de estas sustancias puede traer riesgos considerables para la salud, incluidas las enfermedades crónicas.

Palabras clave: Anfetaminas; Asistencia farmacéutica; Camión; Controladores.

\section{Introdução}

Nos dias atuais os caminhoneiros são fundamentais na garantia da qualidade de vida da população, eles giram a economia do país com o transporte de cargas, de alimentos, materiais, medicamentos e muitas vezes necessitam fazer uma jornada ininterrupta em suas viagens para garantir que a mercadoria chegue e tempo hábil ao seu destino. Alguns profissionais devido ao desgaste físico durante o trajeto utilizam anfetaminas na expectativa de chegar mais rápido, essas medidas inúmeras vezes são tomadas por fatores que os deixam em situações estressantes (Belan, 2017).

Anfetaminas são classes de substâncias psicoativas, cuja estruturas são semelhantes a adrenalina, derivada das feniletilaminas, estimulantes do sistema nervoso central (Araújo, 2019).

Esse produto também começou a ser usado como descongestionante nasal e somente em 1937 a substância passou a ser comercializada de forma controlada, em decorrência de suas ações estimulantes que levavam o usuário a estado de euforia com diferentes sensações incluindo o estado de alerta e posteriormente surgiam as consequências daquele uso e o indivíduo voltava ao seu mundo, porém com o Sistema Nervoso Central abalado (Galamba, 2017).

As anfetaminas deixam o usuário em estado de vigília aumentando a autoconfiança e consequentemente o risco de tomar decisões rápidas pelo efeito da substância no seu organismo, tornando preocupante seu uso no trânsito, vários são os casos que essa situação prejudica a vida de vários condutores levando a acidentes incluindo vítimas fatais devido os efeitos rebotes (Fonseca, 2019).

O uso excessivo dessas substâncias por motoristas promove aumento da concentração sanguínea de anfetaminas e a piora de desempenho na direção, que seria o efeito oposto ao desejado durante as viagens (Panizza, 2019).

O combate ao consumo exacerbado de drogas lícitas e ilícitas está se tornando um desafio cada vez maior, devido a sua expansão mundial, sendo considerada uma prática comum desde os princípios da humanidade. As regulamentações exigem a venda de anfetaminas em farmácias e drogarias com retenção de receita, pois elas possuem indicação terapêutica diferentes das procuradas pelos caminhoneiros, mas o comércio oferece facilidades e a aquisição acontece em locais impróprios como postos de gasolina por exemplo (Girotto, 2016).

O uso crônico das substâncias psicoativas traz consigo graves consequências como acidentes, violência interpessoal, distúrbios do sono e dependência física e mental, tornando - se, então, um importante problema a ser controlado (Pereira, 2017). 
O farmacêutico dentro de suas atribuições clínicas tem o dever de realizar orientações prestando assistência farmacêutica dentro das drogarias onde muitas vezes são procurados, bem como realizando ações orientativas mostrando os riscos do uso indiscriminado e irracional das anfetaminas, essas ações deverão ocorrer em locais onde se concentrem o maior número de motoristas possível para que tenham uma compreensão coletiva (Silva, 2020).

Devido à utilização inadequada de anfetaminas nos últimos anos, verificou-se a quantidade de acidentes ocorridos no trânsito e a saúde dos motoristas nas rodovias do Brasil, o papel do farmacêutico é conscientizar os motoristas através da assistência farmacêutica as consequências do uso de anfetaminas e os problemas de saúde que elas podem causar.

\section{Caminhoneiros}

Os caminhoneiros são os profissionais que abastecem os comércios com bens de consumo em todo o país, eles enfrentam situações diversas para transportar suas cargas, algumas perecíveis como alimentos e medicamentos, outras que suportam viagens mais longas como sementes e grãos, materiais da construção civil, maquinários, entre outras, não importando a carga eles devem chegar dentro do prazo estabelecido no local de descarga, porém algumas situações podem levar o motorista a se desgastar durante as viagens como as condições das estradas e rodovias que em alguns estados estão deterioradas e leva a incerteza de ter o seu caminhão em bom estado de funcionamento até o destino e poder retornar em segurança, levando à atrasos em suas viagens, a dificuldade em carregar novamente para voltar ao seu local de origem, o valor dos fretes em relação à manutenção de seus caminhões, são umas das causas que preocupam os caminhoneiros (Belan, 2017).

Cunha (2018), aponta em suas observações que os motoristas também possuem situações conflitantes em suas vidas com vários deslocamentos entre elas a saudade da família que fica em casa e só se unem poucos dias durante os meses, diante disso os motoristas se sentem culpados por não acompanhar o crescimento dos filhos. A solidão que aperta durante as viagens nas estradas é outro fator que atrapalha a vida do caminhoneiro, dentro da cabine do caminhão eles não tem companhia para se distrair, basicamente fazem seus trajetos sozinhos, sem ter um familiar ou colega para revezar.

Alguns profissionais são autônomos e o aumento das viagens são devidos compromissos financeiros que devem ser honrados, devendo o mesmo aumentar o número de entregas no mês e esse inconveniente também levam alguns profissionais a usar a anfetamina (Messias, 2019).

Alguns condutores com a rotina das viagens e seu estilo de vida acabam sobrecarregando o seu organismo com noites sem dormir ou dormindo poucas horas, alimentação irregular, muitos deles só fazem refeições como almoço e jantar ricos em gordura e sódio, com isso, passando bastante tempo sem se alimentar, adquirindo problemas crônicos de saúde como hipoglicemia, hipertensão, diabetes, problemas renais e obesidade, porém os caminhoneiros estão com uma demanda excessiva de trabalho abusando de cafeína, álcool e outras substâncias mais potentes como as anfetaminas que conseguem ser compradas com facilidade em postos de gasolina e conveniências (Nascimento, 2016).

Silva (2017) em suas observações notou que as drogarias são locais de passagem garantida pelos caminhoneiros, lá eles adquirem Medicamentos Isentos de Prescrição como analgésicos, antitérmicos, medicamentos para coluna inclusive medicamentos para agitação nervosa que pode ser causada por uso de anfetaminas e álcool.

\section{Uso de drogas entre caminhoneiros}

Nas estradas e rodovias do país é comum a presença de barreiras interestaduais onde existem profissionais que analisam o estado clínico e toxicológico para verificação de presença de drogas lícitas, ilícitas no organismo do caminhoneiro utilizando para a realização dos exames fios de cabelo, fezes e urina para constatar a presença de drogas. O teste do bafômetro também é utilizado para verificação de presença de álcool no organismo dos motoristas. Existem leis incluindo a 13.103/2015 
denominada a lei do caminhoneiro que proíbem a existência de material toxicológico em exames realizados periodicamente, mais em alguns casos essa lei não inibe o uso de substâncias psicoativas (Lima, 2019).

Bebidas alcóolicas, que por sua vez causam danos ao Sistema Nervoso Central - SNC levando à perda de reflexos, relaxamento ou contração da musculatura, oscilação entre sono e vigília e confusão mental, por vezes o motorista passa por alucinações que o levam a tentar desviar de algo que não existe e invade pista contrária causando acidentes e danos psíquicos irreversíveis (Santos, 2019).

A intoxicação causada por anfetamínicos pode variar de leve a grave, assim como gerar overdose pois o usuário experimenta uma vez e fica estimulado com o efeito e abusa do seu consumo, levando o seu organismo não suportar tamanha oscilação ocasionando problemas de saúde graves ou até mesmo o óbito. A dose letal ainda não é conhecida, mas torna-se um problema quando passa a ter associação com álcool e outras drogas (Nascimento, 2016).

Motoristas que dormiram menos de 5 horas em um período de 24 horas são mais propensos a envolverem-se em acidentes relacionados a sono ao volante que sem perceber possuem lapsos de sono levando a um breve cochilo, o sono perdido raramente pode ser recuperado em sua totalidade causando perda de reflexos, controle de direção, podendo sair da sua direção segura e gerar colisões com outros veículos, capotamentos entre outros acidentes, sendo estes mais frequentes durante a noite, em rodovias, com o motorista sozinho (Belan, 2017).

Várias situações ocorrem nos consultórios farmacêuticos onde o motorista chega com sintomas de sudorese, dor de cabeça, visão turva, oscilações de pressão e querem medicamentos para combater esses problemas, na verdade eles podem portar algum tipo de doença crônica e não terem recebido esse diagnóstico por não procurarem auxílio médico pois a correria do dia - a - dia impede de ir ao hospital e utilizam medicamentos por conta própria agravando seu caso clínico (Girotto, 2016).

\section{Anfetaminas}

Para Galamba (2017) a anfetamina como uma droga sintética, geralmente ingerida por via oral, fabricada pela primeira vez na Alemanha, em 1887. É estimulante do sistema nervoso, tem como efeitos agudos, taquicardia e hipertensão, além de euforia, hiperatividade e insônia.

Em 1945, a anfetamina conquistou grande espaço no mundo, inclusive durante a Segunda Guerra Mundial, os soldados em meio ao cansaço encontraram em seu uso um aliado pois a mesma ofertava os seus efeitos euforizantes diminuindo o sono e o cansaço, aumentando o desempenho físico e intelectual, enquanto o adversário estava com o corpo debilitado eles com o isso conseguiam vencer as batalhas (Batista, 2021).

As anfetaminas são drogas comercializadas em forma de comprimidos, cápsulas, pós e injetáveis, elas são facilmente vendidas, frequentemente utilizadas, parecendo haver um aumento global do seu consumo. Estas substâncias podem induzir sintomas psicóticos em indivíduos saudáveis, essa droga por ter um efeito agressivo pode causar adoecimento e o caminhoneiro não conseguir mais realizar as suas viagens com a mesma rapidez e frequência, o corpo não responde mais aos estímulos devido à dependência, como o uso é feito de maneira automática não existe nenhum tipo de atenção farmacêutica durante a dispensação com isso o motorista ingere o produto sem ter ideia do que poderá ocorrer no seu organismo (Gouveia, 2017).

\section{Mecanismo de ação}

As anfetaminas são fortes estimulantes do sistema nervoso central - SNC, com enormes propriedades aditivas, atuam diretamente no sistema de recompensa mesolímbico dopaminérgico, induzindo a libertação de dopamina e noradrenalina nas fendas sinápticas do nucleus accumbens e noutras áreas terminais, em outras palavras, elas aumentam os níveis sinápticos de dopamina e bloqueiam a recaptação (Gouveia, 2017). 
Sua ação no hipotálamo reduz a atividade gastrointestinal e inibe o apetite tendo quadro de hipoglicemia, com esse efeito o motorista pode ter sensação de visão turva, sudorese, provocando desmaios, em muitos casos os caminhoneiros não se alimentam com frequência e mesmo assim estão acima do peso, é comum a verificação de circunferência abdominal maior que o esperado podendo ser uma das causas a dificuldade de evacuar e a pouca hidratação, para evitar muitas paradas e o caminhoneiro atrasar sua chegada (Galamba, 2017).

As anfetaminas: Induzem a libertação exocítica de DA e 5-HT das suas vesículas de armazenamento; induzem a sua libertação não exocítica (por transporte reverso); diminuem a sua recaptação celular; possuem propriedades inibitórias da MAO (Pereira, 2017).

\section{Efeitos adversos}

Fonseca et al. (2019), em suas observações afirma que alguns efeitos posteriores das anfetaminas sobre o usuário são a fadiga e sonolência substituindo o efeito estimulante, a droga deixa o corpo do condutor e o cansaço domina deixando - o mais suscetível a situações negativas no trânsito levando à sérias consequências como dormir ao volante causando acidentes.

Os sinais e sintomas de uma pessoa que ingeriu esta droga são: midríase, xerostomia, taquipnéia, taquicardia, ranger dos dentes, uma sensação de poder e a fala fica "atropelada", euforia, com intensa liberação de energia e sensação de bemestar, alegria e alívio na fadiga (Andrade, 2020).

Os psicoestimulantes já causam uma desordem nos estímulos fisiológicos e aqueles motoristas que se privam do sono ou que dormem por um tempo reduzido se tornam inquietos e para compensar o organismo e ficar mais alertas realizam a combinação de café e energéticos com anfetaminas, essa junção pode desencadear problemas como arritmias levando desde um simples descompasso dos batimentos até o quadro de infarto agudo do miocárdio (Belan, 2017).

Aqueles condutores que já possuem predisposição para doenças crônicas com a qualidade de vida que possuem automaticamente desencadeiam hipertensão, diabetes, problemas renais por ficarem horas sem ir ao banheiro tendem a ficar inchados pela retenção de líquidos e problemas circulatórios por permanecerem horas à fio sentados, sem alongar as pernas, aumentam também os riscos de problemas cardiovasculares e poderão tornar usuários de medicamentos contínuos para garantir o seu bem - estar (Fonseca, 2019).

\section{Assistência farmacêutica no estilo de vida do caminhoneiro prevenido as consequências do uso de anfetaminas}

Algumas contratantes no ato da admissão acabam exigindo que seus colaboradores realizem em menos tempo possível as viagens independentes da forma que isso seja feito, com tamanha responsabilidade os condutores utilizam as anfetaminas para potencializar o seu tempo acordado e dirigir em horários mais estendidos conseguindo entregar sua carga (Silva, 2017).

Os motoristas de caminhão são compostos por homens e mulheres, em sua maioria do sexo masculino, e essa classe está bastante vulnerável ao surgimento de patologias relacionadas ao estilo de vida dos mesmos que devido a rotina de viagens não conseguem agendar uma consulta e os sintomas iniciais de tornam habituais devendo ter acompanhamento através de medidas farmacológicas e não farmacológicas (Girotto, 2016).

A rotina dos caminhoneiros também se compromete com a presença de drogas, muitos possuem doenças crônicas e utilizam medicamentos por exemplo para hipertensão, diabetes e hipercolesterolemia utilizando de modo contínuo e a associação desses medicamentos com o álcool e as anfetaminas tem a redução de seu potencial de ação. Medidas não farmacológicas podem ser adotadas para que esse quadro de saúde não seja agravado (Silva, 2017).

Para Nascimento (2016) Os efeitos deletérios do uso de anfetaminas podem ser agudos ou crônicos, como insônia (tempo prolongado de vigília e organismo não consegue voltar à rotina anterior, alucinações, agressividade, inapetência, sudorese, taquicardias, tremores, intoxicações, dependência e morte súbita. 
Quando interrompido o seu uso, a pessoa sente astenia (falta de energia) e torna-se incapaz de realizar tarefas antes habituais, sentindo-se deprimida. Esta droga provoca tolerância, de maneira que, para experimentar os mesmos efeitos, o usuário precisa aumentar a dose a cada dia (Galamba, 2017).

Os farmacêuticos são os profissionais mais procurados pelos caminhoneiros por serem os profissionais de mais fácil acesso, eles estão presentes em farmácias e drogarias e conduzem atendimentos a esses motoristas por motivos como insônia, fadiga, dores musculares, azia e queimação e diarreia, eles vão as drogarias para comprar um remédio e minimizar a situação, o correto era se fazer o uso adequado de alimentos e melhorar o estilo de vida (Caitano $\left.{ }^{1}, 2017\right)$.

A assistência farmacêutica deve ocorrer onde os motoristas se encontram, medidas educativas em estradas, postos com noções de cuidados com a própria saúde em relação a consultas de rotina, realizações de exames periódicos, alimentação balanceada, o uso irracional de medicamentos, anfetaminas, álcool e cigarro para que juntos possamos oferecer qualidade de vida para os caminhoneiros e eles prestando um serviço com qualidade e segurança nas estradas, protegendo a vida de todos, sem risco de acidentes (Girotto, 2016).

\section{Metodologia}

Este é um estudo que se caracteriza por uma revisão integrativa. Considera-se uma revisão integrativa de literatura um método que permite a síntese de conhecimento e a incorporação dos resultados de estudos significativos na prática (de Sousa, 2017). O período que compôs a elaboração deste trabalho foi do ano de 2013 a 2021. As informações aqui descritas foram coletadas no Google Acadêmico e Scientific Eletronic Library Online (SciELO), com o uso dos descritores: Anfetaminas; assistência farmacêutica; caminhão; motoristas e seus respectivos correspondentes em inglês. A partir desses descritores e para a busca dos artigos, através dos filtros das próprias bases de dados, estabeleceram-se os seguintes critérios de inclusão: artigos disponíveis na íntegra, em português e inglês, no período de 2016 a 2021 com acesso gratuito e que tivessem afinidade com a temática. Identificaram-se no total 40 publicações, após aplicação dos critérios de inclusão, foram excluídos 20 estudos identificados por meio de pesquisas em outras fontes de dados, permanecendo 20 estudos. Os resultados apresentados acima foram dispostos no Fluxograma 1.

Fluxograma 1: Fluxograma das etapas de inclusão e exclusão dos artigos (dados dos artigos utilizados).
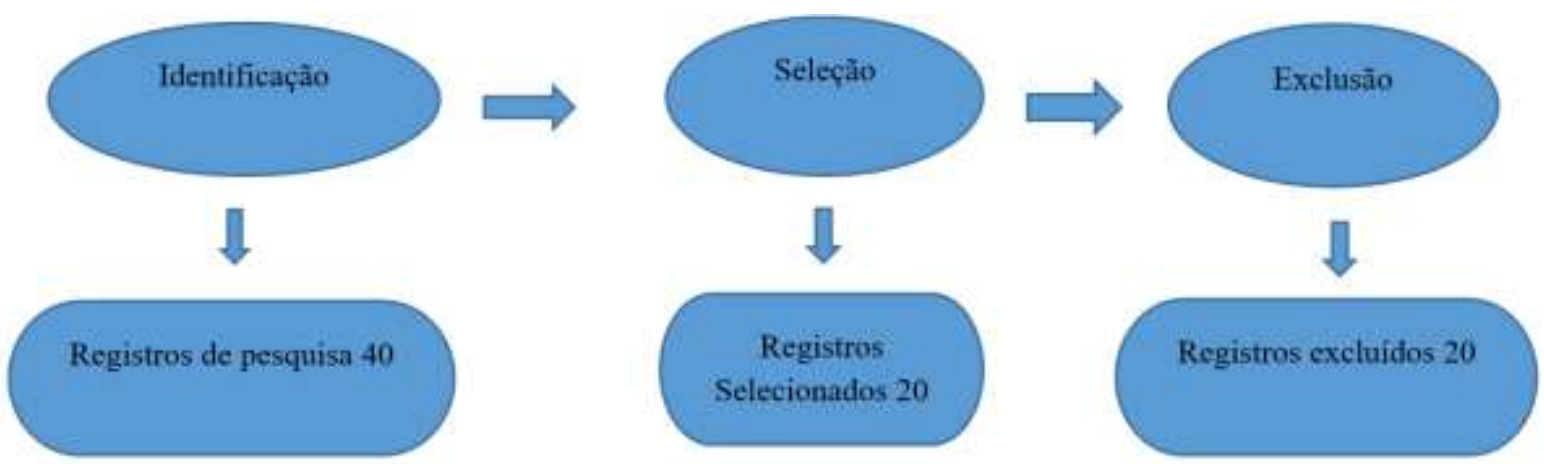

Fonte: Assistência farmacêutica nas consequências do uso de anfetaminas por motoristas de caminhão: Revisão integrativa.

Para a identificação dos documentos de interesse para estudos foi observado o título e o resumo dos artigos, elegendo os utilizados. Foram desconsiderados todos aqueles que não contemplavam o tema.

\section{Resultados}

Entre os 8 artigos selecionados, 3 são revisões descritivas, 1 é revisão bibliográfica, 2 são revisões transversais e 2 de revisões descritivas/experimentais. O perfil e características dos estudos estão apresentados na Tabela 1. 
Tabela 1: Estudos selecionados segundo autoria, ano de publicação, título, revista e base de dados dos estudos selecionados.

\begin{tabular}{|c|c|c|c|}
\hline AUTOR/ANO & OBJETIVO & DESENHO DO ESTUDO & DESFECHO \\
\hline $\begin{array}{l}\text { Nascimento Junior et al. } \\
\text { (2016). }\end{array}$ & $\begin{array}{l}\text { Verificar a prevalência e fatores associados à } \\
\text { utilização autorrelatada de anfetaminas entre } \\
\text { caminhoneiros que trafegam na rodovia BR } \\
\text { 251, no trecho de Montes Claros, MG, com } \\
\text { parada em um posto de combustível. }\end{array}$ & Revisão Descritiva. & $\begin{array}{l}\text { O uso de anfetaminas esteve associado aos profissionais mais jovens } \\
\text { e com maior carga horária de trabalho. Faz-se necessário um controle } \\
\text { maior sobre a venda desses medicamentos por parte dos órgãos } \\
\text { competentes. }\end{array}$ \\
\hline Belan et al. (2017). & $\begin{array}{llll}\text { Compreender a experiência } & \text { subjetiva } & \text { de } \\
\text { caminhoneiros em relação } & \text { ao uso } & \text { de } \\
\text { substâncias psicoativas. } & & \end{array}$ & Revisão Bibliográfica. & $\begin{array}{l}\text { Há uma divergência de opiniões que enfraquece a categoria em } \\
\text { relação à negociação por melhores condições de trabalho, ao mesmo } \\
\text { tempo que o uso de substâncias ilícitas é considerado normal e não é } \\
\text { questionado por parte dos participantes. }\end{array}$ \\
\hline Caitano (2017) & $\begin{array}{l}\text { Analisar a necessidade do cuidado farmacêutico } \\
\text { voltado para os pacientes caminhoneiros do } \\
\text { Norte de Minas, vulneráveis à hipertensão } \\
\text { arterial e diabetes mellitus adquiridos em } \\
\text { consequência do hábito de vida inadequado. }\end{array}$ & Estudo Transversal & $\begin{array}{l}\text { A procura pelo cuidado farmacêutico por esses pacientes é baixa e } \\
\text { ainda são esquecidos pelo sistema de saúde, os tornando-os mais } \\
\text { vulneráveis a certos tipos de patologias. }\end{array}$ \\
\hline Pereira (2017). & $\begin{array}{l}\text { Investigar o uso indiscriminado de anfetaminas } \\
\text { entre motoristas profissionais }\end{array}$ & Revisão Descritiva / Experimental & $\begin{array}{l}\text { As anfetaminas fazem parte do cotidiano da maioria dos } \\
\text { caminhoneiros de longas distâncias e sugere-se a necessidade de } \\
\text { realização de campanhas informativas sobre os riscos associados ao } \\
\text { uso indiscriminado de "rebites". }\end{array}$ \\
\hline Cunha (2018). & $\begin{array}{l}\text { Problematizar a situação de invisibilidade, com } \\
\text { que é submetida está profissão responsável pelo } \\
\text { transporte de boa parte da produção da região, e } \\
\text { também analisar a realidade de exploração } \\
\text { vivenciada no seu trabalho, agravada com a } \\
\text { recente aprovação da Lei n }{ }^{\circ} 13.103 \text {, de } 17 \text { de } \\
\text { abril de 2015, chamada de Lei do } \\
\text { Caminhoneiro. }\end{array}$ & Revisão Descritiva / Experimental & $\begin{array}{l}\text { Pode-se até pensar que é uma profissão da liberdade por se } \\
\text { movimentarem para lugares diferentes, rodando pelo país até } \\
\text { perderem as contas da quilometragem percorrida. Mas, no real, não } \\
\text { tem nada de glorioso nesta profissão. Este voo de "condor" solitário } \\
\text { faz dessa rotina do desapego um forte aliado, que deixa os } \\
\text { profissionais doentes e abandonados à própria sorte por terem } \\
\text { deixado a vida passar pelo para-brisa do caminhão. Os caminhoneiros } \\
\text { vivem se despedindo de seus familiares, pois têm uma possibilidade } \\
\text { angustiante de não voltarem com vida para seu lar. O trabalho devia } \\
\text { proporcionar o bem-estar aos indivíduos, estar integrado à vida, ter } \\
\text { um sentido, não se restringindo a um meio sofrido de sobrevivência. }\end{array}$ \\
\hline Lima et al. (2019). & $\begin{array}{l}\text { Analisar a prevalência do uso de anfetaminas } \\
\text { por motoristas de caminhões. }\end{array}$ & Revisão Descritiva. & $\begin{array}{l}\text { Através dos resultados encontrados, pode-se observar a não } \\
\text { ocorrência de uma redução significativa da prevalência do uso de } \\
\text { anfetaminas entre os anos de } 2013 \text { e } 2016 \text {. }\end{array}$ \\
\hline
\end{tabular}


Research, Society and Development, v. 10, n. 15, e12101522895, 2021

(CC BY 4.0) | ISSN 2525-3409 | DOI: http://dx.doi.org/10.33448/rsd-v10i15.22895

\begin{tabular}{|c|c|c|c|}
\hline Panizza (2019) & $\begin{array}{l}\text { Estimar a prevalência de anfetamina, cocaína e } \\
\text { maconha, bem como dos medicamentos } \\
\text { benzodiazepínicos e antidepressivos tricíclicos } \\
\text { em população de caminhoneiros que } \\
\text { trafegavam por rodovias federais paulistas no } \\
\text { ano de } 2016 \text {. }\end{array}$ & Estudo Transversal & $\begin{array}{l}\text { A prevalência do uso das drogas ilícitas abordadas no presente estudo } \\
\text { - especialmente das drogas estimulantes - ainda é grande na } \\
\text { população de motoristas de caminhão brasileiros, apesar da } \\
\text { ocorrência de modificações legislativas que poderiam favorecer a } \\
\text { diminuição do uso tanto laboral como recreativo por essa classe de } \\
\text { trabalhadores, tendo se mostrado mais susceptíveis ao uso os } \\
\text { caminhoneiros mais jovens, solteiros, que declararam estar a menos } \\
\text { tempo exercendo a profissão, que se declararam caminhoneiros de } \\
\text { longa distância e que percorriam grandes distâncias no atual trajeto. }\end{array}$ \\
\hline Batista et al. (2021). & $\begin{array}{l}\text { Conhecer a percepção de saúde e sua relação } \\
\text { com as condições de trabalho entre } \\
\text { caminhoneiros do estado de Sergipe, Brasil. }\end{array}$ & Revisão Descritiva. & $\begin{array}{l}\text { Sugere-se a realização de novos estudos qualitativos, com outras } \\
\text { técnicas de coleta de informações e uso da triangulação de dados, } \\
\text { para conhecer as possíveis soluções sob a ótica desse grupo e } \\
\text { aprofundar a perspectiva do trabalho, saúde e autocuidado entre os } \\
\text { caminhoneiros. Ademais, explorar esse contexto em outras regiões do } \\
\text { país pode evidenciar diferenças e semelhanças socioculturais que } \\
\text { corroborem com as estratégias de intervenção. }\end{array}$ \\
\hline
\end{tabular}

Fonte: Assistência farmacêutica nas consequências do uso de anfetaminas por motoristas de caminhão: Revisão integrativa. 


\section{Discussão}

O uso de anfetaminas por motoristas de caminhão é vista com frequência principalmente entre os mais jovens que o organismo está integro, suportam uma jornada maior entre uma viagem e outra levando os mesmos por não medirem tanto as consequências a utilização de álcool, café, drogas e substâncias psicoativas por longos períodos, tornando o seu uso abusivo (Nascimento Junior et al., 2016).

Para Belan et. al, (2017) as condições trabalhistas também podem ser uma das motivações que os motoristas encontram para justificar o uso de anfetamínicos, a jornada é longa, as cargas muitas vezes perecíveis estão sujeitas a deteriorar por conta da demora para chegar ao destino, seja por problemas nos caminhões que estragam em meio às estradas, o preço dos fretes que nem sempre cobrem os prejuízos das manutenções, as rodovias em péssimo estado de conservação levam os caminhoneiros a utilizar dessas substâncias para melhorar o seu rendimento por mais horas noite à dentro para que cumpra com os prazos estabelecidos pelos contratantes.

Na vida pessoal dos motoristas de caminhão com a constante agitação entre uma viagem e outra não sobra espaço para cuidar da sua saúde, principalmente no que tange as consequências causadas pelo estilo de vida, grande parte são sedentários, praticam etilismo e tabagismo, alimentam - se de modo incorreto com grandes intervalos entre refeições compostas por alimentos ricos em sódio, gordura e açúcares que são portas de entrada para o desenvolvimento de doenças crônicas como hipertensão, diabetes, colesterol, problemas circulatórios, cardiovasculares, entre outros, buscando na assistência farmacêutica a solução para esses problemas (Caitano, 2017).

Diante desse quadro os farmacêuticos são a melhor ferramenta para realizar ações preventivas nas estradas, postos, restaurantes, alcançando com informações importantes motoristas jovens ou mais experientes que já utilizaram "rebites" durante o seu trabalho nas estradas pensando não haver problemas futuros, incluindo nessas orientações as consequências do uso das anfetaminas (Pereira, 2017).

Cunha (2018), ressalta que muitos caminhoneiros por verem nessa profissão sinônimo de liberdade viajam sozinhos, tendo o rádio como companhia, não se cuidam periodicamente como deveriam e sempre ficam longos períodos fora de seus lares, realizando seu trabalho para levar o sustento para sua família que descansa o coração quando os vêm de volta.

Apesar da realização de eventos para conscientizar sobre as consequências do uso abusivo das anfetaminas muitos motoristas persistem na utilização por despertar durante as viagens efeitos como aumento do tempo em vigília e reflexos, autoconfiança, mais ao terminar os efeitos o organismo responde com sinais que podem colocar a sua vida e de várias pessoas em risco pela presença de sono ao volante, perda de reflexos, alucinação, sudorese, taquicardia debilitando mais o usuário a cada uso (Lima et. al, 2019).

Segundo Panizza, 2019 não bastasse os caminhoneiros ingerirem as anfetaminas em altas doses para suprir suas necessidades ainda associam com outras drogas que vão degradando suas atividades cerebrais de modo irreversível, muitos sentem falta de memória, não conseguem ter um sono restaurador, desencadeando vários problemas de saúde.

Para Batista et. al. (2021), a assistência farmacêutica assim como os demais profissionais deve ficar monitorando as demandas em relação à saúde do caminhoneiro evitando que eles deixem os efeitos dos anfetamínicos encerrarem sua carreira que é tão necessária para toda a população.

\section{Considerações Finais}

As anfetaminas são drogas que afetam diretamente o SNC (Sistema Nervoso Central) causando efeitos indesejados nos usuários que podem levar esses pacientes a passarem por períodos de euforia, insônia, sensação de potência e através desses sentimentos o uso dessas drogas estão cada vez mais presentes nas estatísticas que mostram as causas dos desastres nas rodovias. 
Os acidentes são causados após os "benefícios" das anfetaminas acabar e os efeitos provocam ações indesejadas no organismo levando o caminhoneiro a ter alucinações, sonolência, boca seca, movimento agitado das pernas, alterações da libido e agitação nervosa podendo se envolver em acidentes de trânsito prejudicando a si mesmo e outras pessoas que trafegam pelas estradas e em alguns casos mais graves esses acidentes levam a invalidez e a óbitos em ambas as conduções.

A assistência farmacêutica oferece medidas que se adotas pelos profissionais diminuirão as chances de um condutor se envolver em um acidente, são realizadas com efeito de cuidado, estabelecendo meios para que o motorista evite o consumo de tóxicos.

Em suma, os efeitos maléficos superam os benéficos devendo aumentar as fiscalizações e a extinção do consumo errôneo das anfetaminas entre os caminhoneiros e melhorar a qualidade de tráfego seguro no país.

Os farmacêuticos devem voltar seus olhares para os caminhoneiros que necessitam de cuidados com à sua saúde em especial sobre as consequências do uso das anfetaminas que degradam cada vez mais o seu organismo podendo causar danos que os afastem definitivamente da sua profissão.

\section{Implicações práticas}

Recomenda-se a necessidade de estudos complementares quanto a assistência farmacêutica nas consequências do uso de anfetaminas, a fim de enfatizar a importância da assistência na melhoria da qualidade de vida dos caminhoneiros.

\section{Declaração de conflito de interesses}

Os autores declaram que a pesquisa foi conduzida na ausência de quaisquer relações comerciais ou financeiras que possam ser interpretados como um potencial conflito de interesse.

\section{Agradecimentos}

Agradecemos a todos que direta ou indiretamente contribuíram para a realização e sucesso do artigo.

\section{Referências}

Andrade, M. L., Soares, A. C. G. M., dos Santos Sirqueira, R., Souza, V. G., Fraga, R. R. A., Santos, T. L., \& Júnior, A. S. L. (2020). Análise do uso de anfetaminas por universitários de medicina em Sergipe. Revista Eletrônica Acervo Científico, 11, e4243-e4243. https://doi.org/10.25248/reac.e4243.2020.

Araújo, J. S. D. (2019). Consumo de estimulantes cerebrais por estudantes de farmácia da Universidade Federal da Paraíba: prevalência, motivação e efeitos percebidos.

Batista, A. M. F., Ribeiro, R. D. C. L., Barbosa, K. B. F., \& Fagundes, A. A. (2021). Condições de trabalho de caminhoneiros: percepções sobre a saúde e autocuidado. Physis: Revista de Saúde Coletiva, 31. https://doi.org/10.1590/S0103-73312021310206.

Belan, T. O., de OLIVEIRA, C. G. A., de Mattos Machado, S. H., de Souza Brandao, P., \& da SILVA, J. R. G. (2017). Prevalência do uso de anfetaminas por caminhoneiros. Acta Biomedica Brasiliensia, 8(2), 71-82. http://dx.doi.org/10.18571/acbm.141.

Caitano $^{1}$, N. M. B., \& da Mota Junior, P. J. (2017). Estudo sobre a necessidade do cuidado farmacêutico aos pacientes caminhoneiros do norte de minas. Revista Bionorte, 6(1).

Cunha, S. T. (2018). Ser caminhoneiro: as condições adversas de trabalho na região de Rondonópolis.

França $^{1}$, L. L. A., de Oliveira, M. M., Lemos, V. M., da Costa, K. V. M. C., \& Guedes, D. N. Caracterização das motivações que levam ao potencial uso de anfetaminas por estudantes da ufpb.

Sousa, L. M. M., Marques-Vieira, C. M. A., Severino, S. S. P., \& Antunes, A. V. (2017). A metodologia de revisão integrativa da literatura em enfermagem. $N^{\circ} 21$ Série 2-Novembro 2017, 17.

Fonseca, J. G., Viana, G. M., de Souza, J. E. M., \& Rossi-Barbosa, L. A. R. (2019). Fatores associados ao uso de anfetaminas entre caminhoneiros. Revista Interdisciplinar de Estudos em Saúde, 116-125. https://doi.org/10.33362/ries.v8i1.1474.

Galamba, M. A. F. (2017). Uso terapêutico e recreacional de anfetaminas e derivados: riscos e benefícios (Doctoral dissertation).

Girotto, E., Guidoni, C. M., González, A. D., Mesas, A. E., \& Andrade, S. M. D. (2016). Uso contínuo de medicamentos e condições de trabalho entre motoristas de caminhão. Ciência \& Saúde Coletiva, 21, 3769-3776. https://doi.org/10.1590/1413-812320152112.24212015. 
Gouveia, P. J. B. Psicoses induzidas por anfetaminas: Um trabalho de revisão. Dissertação mestrado (Medicina). Faculdade de Medicina Universidade do Porto - UFMUP. Março, 2017.

Lima, B. M. Y.; Teles, I. C. J.; Montalvão, J. R.; Potenciano, N. L. B. C.; Leite, R. S. Análise do perfil e do consumo de drogas por caminhoneiros durante a renovação da carteira nacional de habilitação, em um laboratório de Anápolis - Goiás. Trabalho de Conclusão de Curso (Medicina), Centro Universitário de Anápolis - UniEVANGÉLICA. Anápolis - GO, 2019.

Lima, L. P., \& Costa, L. D. A. (2021). Estudo clínico-epidemiológico de HIVpositivos acompanhados em um serviço de assistência especializada. Arquivos de Ciências da Saúde, 28(1). https://doi.org/10.17696/2318-3691.28.1.2021.1753.

Messias, J. C., Cavieres-Higuera, H., Silva, R. A., Facundo, G. N. D. S., \& Lessa, R. T. (2019). Ser caminhoneiro no Brasil: dos autoestereótipos implícitos à justificação de sistema. Estudos de Psicologia (Campinas), 36. http://dx.doi.org/10.1590/1982-0275201936e180139.

Nascimento, P. F., \& Junior, G. A. (2016). Implicações do uso de drogas e a condição de saúde dos caminhoneiros. Psicologia e Saúde em debate, 2(Ed. Esp. 1), 104-116. https://doi.org/10.22289/2446-922X.V2EEA8.

Panizza, H. D. N. Prevalência do uso de drogas ilícitas e medicamentos por motoristas de caminhão que trafegam em rodovias do estado de São Paulo (Doctoral dissertation, Universidade de São Paulo). https://doi.org/10.11606/D.5.2020.tde-15032021-223034.

Pereira, A. M., \& de Souza, F. H. V. (2017). Avaliação do uso de anfetamínicos entre caminhoneiros de longa distância. Polêm! ca, 17(4), 016-029. https://doi.org/10.12957/polemica.2017.34271.

Santos, T. C. As repercussões administrativas de conduzir veículo automotor sob a influência de álcool: um estudo sobre o confronto entre o princípio da segurança viária e as garantias do processo acusatório. Trabalho de Conclusão de Curso - (Direito). Universidade Católica do Salvador - UCSAL. Salvador, 2019.

Silva, R. A. (2020). A realidade dos caminhoneiros brasileiros de acordo com a teoria de justificação do sistema. 